\title{
Spectrometric Studies and Semi-Empirical Calculations of Some Thiomorpholides
}

\author{
Patricia E. Allegretti ${ }^{1}$, Danila Ruiz ${ }^{1}$, Eduardo A. Castro, ${ }^{* 2}$ and Jorge J.P. Furlong ${ }^{1}$ \\ ${ }^{1}$ Laboratorio de Estudio de Compuestos Orgánicos (LADECOR), División Química Orgánica, Departamento de \\ Química, Facultad de Ciencias Exactas, Universidad Nacional de La Plata, (1900) La Plata, Buenos Aires, Argentina \\ ${ }^{2}$ INIFTA (UNLP-CONICET-CIC), Departamento de Química, Facultad de Ciencias Exactas, Universidad Nacional de \\ La Plata, Diagonal 113 y 64, Suc. 4, C. C. 16, (1900) La Plata, Buenos Aires, Argentina
}

\begin{abstract}
Mass spectra of selected thiomorpholides have been analysed and specific fragmentation assignments have been done to characterised and weigh co-existing keto and enol tautomers. The predictive value of this methodology in regard to keto-enol equilibria occurring in gas phase is not only supported by the influence of substitution nature and size of these but also by the good correlation found between the selected fragments abundances ratio, semi-empirical calculation (AM1) of the corresponding heats of tautomerization and nuclear magnetic resonance data. The results show that the thioketo-thioenol equilibrium can be studied by mass spectrometry where ionization in the ion source has a negligible effect on the position of that equilibrium and by GC/MS where solvent separation in the analytical column seems to preclude shifts from the equilibrium reached at the injection port of the gas chromatograph.
\end{abstract}

Keywords: Tautomerization, thiomorpholides, mass spectrometry, theoretical calculations, AM1 semi-empirical molecular orbital method.

\section{INTRODUCTION}

Among the members of the family of thioamides (compounds of interest in several application areas, not only as intermediates of synthesis $[1,2]$ but also in the field of the chemistry of peptides [3]), the thiomorpholides are particularly interesting since not only they exhibit diverse biological activity [4-6] but also they are the synthesis precursors of organic compounds such as substituted thiophenes which are present in natural products [7].

In this work m.s. and n.m.r data and semi-empirical calculations are employed to study the tautomeric thioketothioenol equilibria for a group of selected thiomorpholides (Fig. 1).

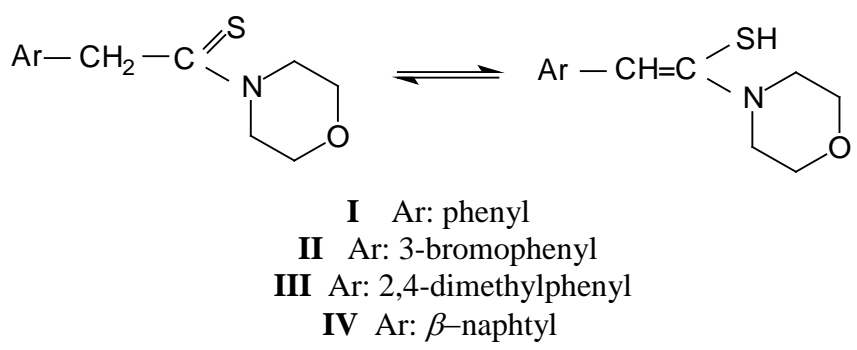

Fig. (1). Thioketo-thioenol equilibria of the thiomorpholides under study.

\footnotetext{
*Address correspondence to this author at the INIFTA (UNLP-CONICETCIC), Departamento de Química, Facultad de Ciencias Exactas, Universidad Nacional de La Plata, Diagonal 113 y 64, Suc. 4, C. C. 16, (1900) La Plata, Buenos Aires, Argentina; Tel: 54-221-4257430; Fax: 54-221-4254642; Email: castro@quimica.unlp.edu.ar
}

In order to know the effect of the morpholide group on the tautomers distribution the corresponding behavior was compared with that of N,N-dimethylethanethioamide.

Mass spectrometry data seem to be very informative for studying and identifying tautomers, because external factors like solvents, intermolecular interactions, etc., can be excluded by transferring the tautomeric system into gas phase, where the process becomes truly unimolecular [8]. As it has been demonstrated in the case of keto-enol tautomerism of a series of 1- and 3-substituted acetylacetones [9] and a variety of carbonylic and thiocarbonilic compounds [10-17], there is no significant interconversion of the tautomeric forms in the gas phase following electron impact ionization in the mass spectrometer (molecular ions, $\mathrm{M}^{+^{\bullet}}$, do not seem to undergo unimolecular tautomerization) and, even more surprising, for GC/MS experiments, once the solvent is separated after injection in the injection port of the gas chromatograph, tautomerism mechanisms (intermolecular, unimolecular) would not seem to take place even with no GC separation (under the selected experimental conditions). These conclusions are supported by temperature studies at the ion source (negligible effect) and at the injection port of the gas chromatograph with a shifting effect in agreement with the corresponding heats of tautomerization [10]. In fact, this process would take place very fast under the working conditions in the GC.

Separation of the tautomers in the analytical column are usually very difficult, consequently, the different pathways of fragmentation of the tautomeric forms have to be used for identification of the individual tautomers [10]. For this reason and because of the high similarity between MS (commercial databases) and GC/MS spectra, analytical separation has not been considered critical for the present work. Analo- 
gously, it is thought that most of the conclusions could be useful to analyze spectra registered with mass spectrometers equipped with direct insertion probes.

The results obtained by GC/MS when correlated with those from semi-empirical molecular orbital calculations for amides, ureas, hydantoins, isoquinolinones, ketones, diketones, lactones, demonstrate that mass spectrometry constitute an adequate tool for predicting tautomeric equilibrium shifts within a family of organic compounds [10-17]. As mentioned above, tautomerism for some thiomorpholides is studied by resorting to gas chromatography - mass spectrometry and semi-empirical calculations.

\section{MATERIALS AND METHODOLOGY}

\section{General Method of Preparation of Thiomorpholides}

Thiomorpholides were prepared by the Willgerdt-Kindler reaction, modified to improve the yields and the reaction times by microwave irradiation [9].

The reaction was carried out in a household microwave oven by mixing 2 mmoles of acetophenone, 6 mmoles of morpholine and 4 mmoles of sulphur in an open pyrex recipient for 4 minutes at $900 \mathrm{~W}$. Once the reaction mixture is cooled down to ambient temperature $10 \mathrm{ml}$ of dichloromethane were added, the excess sulphur filtered and reduced pressure distillation carried out. The resulting product was eluted in a silica gel column with hexane:ethylacetate 8:2.
The identification was done by mass spectrometry (Fig. 2 and 3 ) by assignment of the corresponding fragment ions (Scheme 1).

N,N-Dimethylethanethioamide was commercially available. All the compounds were identified by ${ }^{1} \mathrm{H}$ n.m.r. (Table 3).

\section{Magnetic Nuclear Resonance Determinations}

The n.m.r. spectra were registered with a Varian Mercury Plus Spectrometer, $200 \mathrm{MHz}$ by dissolution of the selected thiomorpholide in DMSO (10 $\mathrm{mg} / \%)$. The corresponding data is shown in Table $\mathbf{3}$.

\section{Gas Chromatography-Mass Spectrometry Determina- tions}

These determinations were performed by injection of methanol solutions $(1 \mu \mathrm{l})$ in an HP 5890 Chromatograph coupled to an HP 5972 A mass selective detector. An HP5-MS capillary column $(30 \mathrm{~m} \times 0.25 \mathrm{~mm} \times 5 \mu \mathrm{m})$ has been used with helium as the carrier gas $(0.6 \mathrm{ml} / \mathrm{min})$. The temperatures set points were: $200^{\circ} \mathrm{C}$ in the split injector, $300^{\circ} \mathrm{C}$ in the interface, $185^{\circ} \mathrm{C}$ in the ion source and the oven ramp started at $80^{\circ} \mathrm{C}$ and ended at $200^{\circ} \mathrm{C}$ with a heat rate of $10^{\circ} \mathrm{C} / \mathrm{min}$. The electron energy was $70 \mathrm{eV}$ and the pressure in the mass spectrometer was lower than $10^{-5}$ torr, thus precluding ion molecule reactions and the mass range was 50-350 amu.
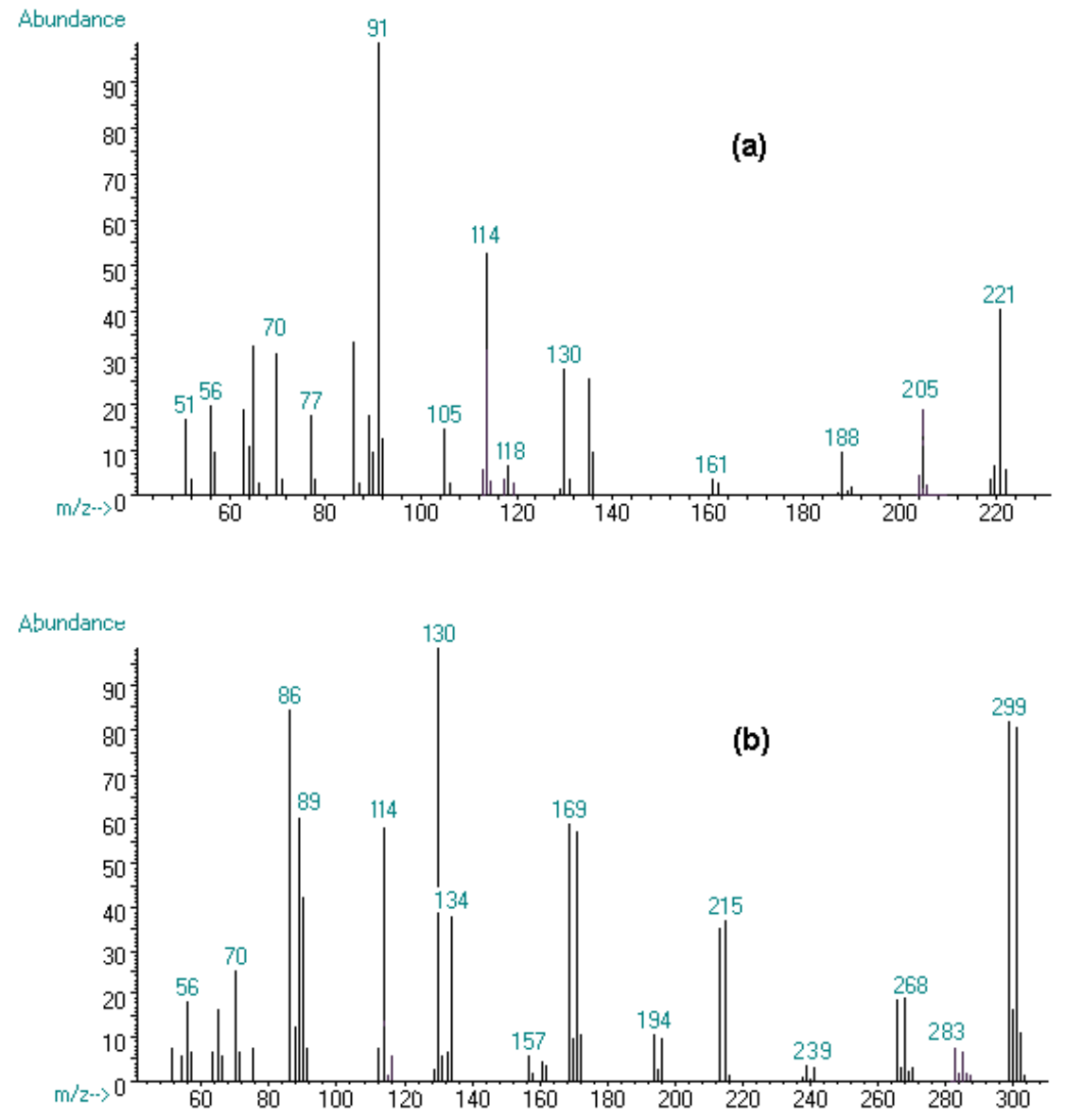

Fig. (2). Mass spectra of (a) 2-Phenylethanethiomorpholide (I) and (b) 2-(3-Bromophenyl)ethane thiomorpholide (II) and their coexisting thioenols. 

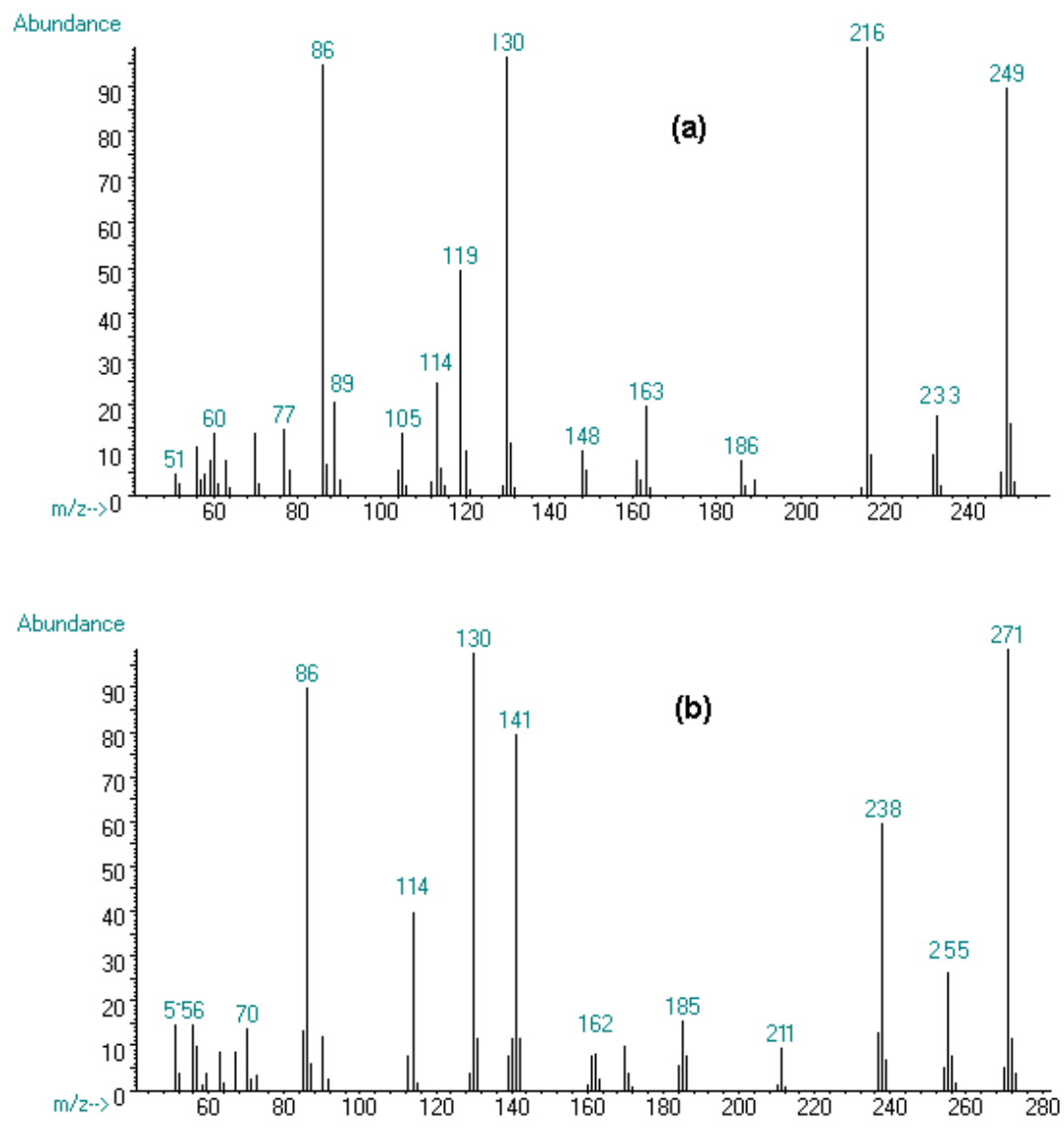

Fig. (3). Mass spectra of (a) 2-(2,4-Dimethylphenyl)ethanethiomorpholide (III) and (b) 2-( $\beta$-Naphtyl) ethanethiomorpholide (IV) and their coexisting thioenols.
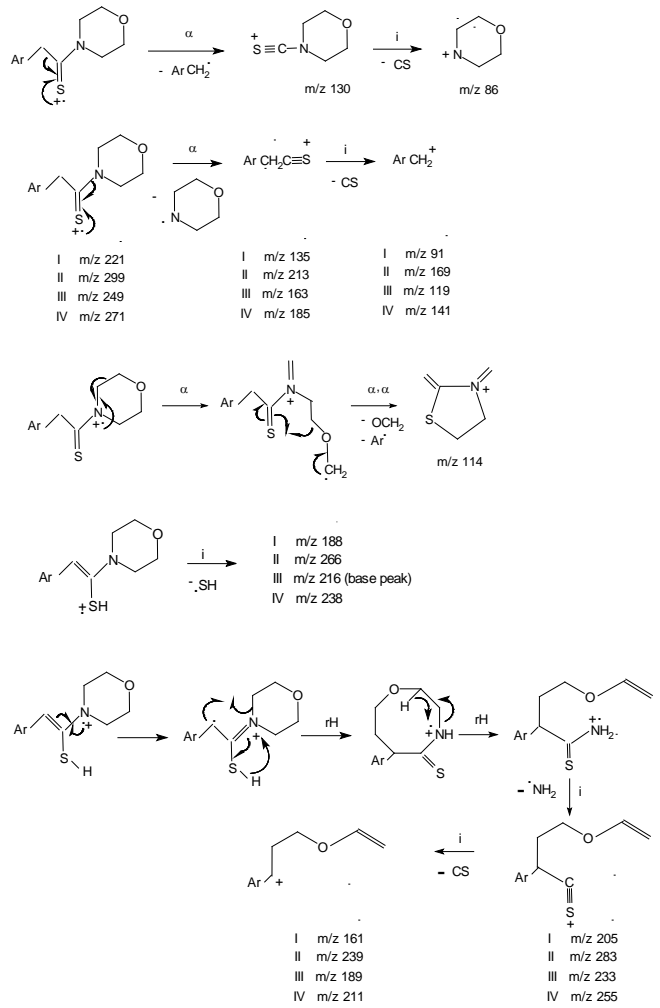

Scheme 1. Main fragmentation pathways for the selected thiomorpholides: 2-Phenylethanethiomorpho-lide (I), 2-(3-Bromophenyl) ethanethiomorpholide (II), 2-(2,4-Dimethylphenyl)ethanethiomorpholide (III) and 2-( $\beta$-Naphtyl) ethanethiomorpholide (IV). 


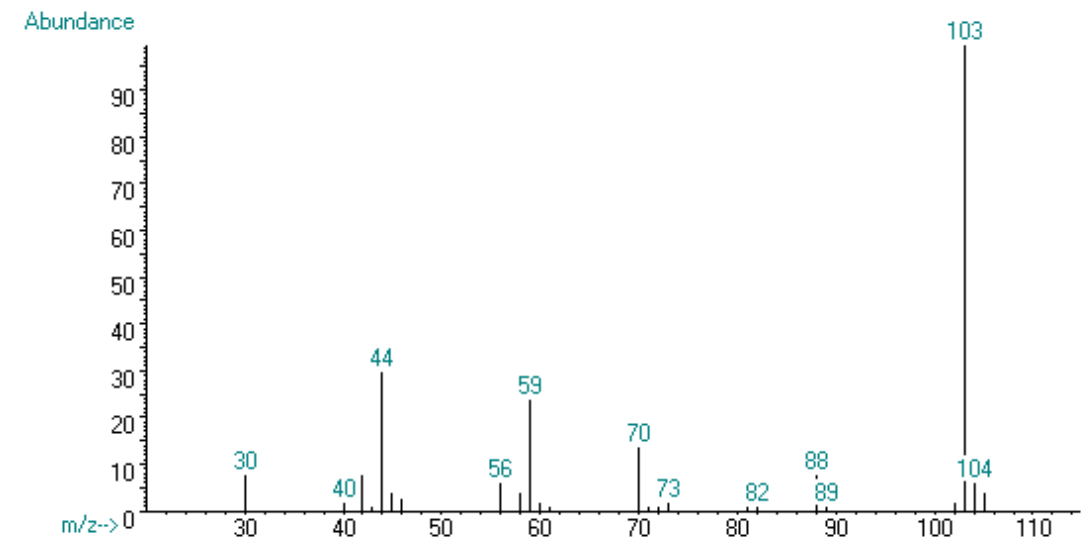

Fig. (4). Mass spectrum of N,N-Dimethylethanethioamide and its coexisting thioenol.

\section{Computational Procedure}

AM1 calculations [18] were performed using the standard Hyperchem package [19]. Since we resorted to heat of formation values in order to rationalize experimental findings and the AM1 technique has been specially parameterized to reproduce this sort of experimental data, we deem this choice is a sensible one for the molecular set under consideration. Besides, previous computations obtained for this sort of studies have given quite sensible results in order to correlate experimental and theoretical data, so that we deem it is not necessary to resort to higher levels of molecular electronic structure sophistication.

\section{RESULTS}

Mass spectra of 2-phenylethanethiomorpholide (I); 2-(3bromophenyl)ethanethiomorpholide (II), 2-(2,4-dimethylph- enyl)ethanethiomorpholide (III) and 2- $\beta$-naphtyl)ethanethiomorpholide (IV) (Figs. $\mathbf{2}$ and $\mathbf{3}$ ) were analyzed. Additionally the mass spectrum of the N,N-dimethylethanethioamide (Fig. 4) was studied to compare its tendency to form the enol tautomer with that of the thiomorpholides.

Table 1 depicts mass spectral data which is relevant to the study of tautomerism of these compounds.

Since coexisting tautomers are not separated by chromatography in the working conditions, the mass spectra are the result of mass spectra superposition (which is also the case of the mass spectra in commercial databases), so that adequate fragments should be selected for proper comparison. $(\mathrm{M}-\mathrm{SH})^{+}$and $\left(\mathrm{CSNC}_{4} \mathrm{H}_{4} \mathrm{O}\right)^{+}$were selected and assigned to the thioimidol and thioamide forms respectively. The approach consists in using the abundances ratio $(\mathrm{M}-\mathrm{SH})^{+} /$

Table 1. Ion Abundances of Selected Mass Spectral Data of Some N,N-Disubstituted Thioamides

\begin{tabular}{|c|c|c|c|c|}
\hline Compound & $\mathbf{M}^{+}$ & $(\mathbf{M}-\mathbf{S H})^{+}$ & $\left(\mathrm{CSNC}_{4} \mathrm{H}_{8} \mathrm{O}\right)^{+}$ & $(\mathrm{M}-\mathrm{SH})^{+} /\left(\mathrm{CSNC}_{4} \mathrm{H}_{8} \mathrm{O}\right)^{+}$ \\
\hline 2-(3-Bromophenyl)ethanethiomorpholide (II) & 107.3 & 24.9 & 129.6 & 0.19 \\
\hline 2-(2,4-Dimethylphenyl)ethanethiomorpholide (III) & 113.1 & 124.4 & 121.9 & 1.02 \\
\hline 2-( $\beta$-Naphtyl)ethanethiomorpholide (IV) & 138.3 & 86.0 & 139.5 & 0.62 \\
\hline
\end{tabular}

*The structures of this fragment ion is $\left(\mathrm{CSN}\left(\mathrm{CH}_{3}\right)_{2}\right)^{+}$.

Table 2. Heats of Formation Differences for Enol-Keto Tautomerization of Selected N,N-Disubstituted Thioamides and Correlation with Mass Spectral Data*

\begin{tabular}{|l|l|l|l|}
\hline Compound & $\begin{array}{l}\Delta \mathbf{H}_{\mathrm{f}} \text { enol- } \Delta \mathbf{H}_{\mathrm{f}} \text { keto } \\
\text { (Neutral molecules) }\end{array}$ & $\begin{array}{l}\Delta \mathbf{H}_{\mathrm{f}} \text { enol- } \Delta \mathbf{H}_{\mathrm{f}} \text { keto } \\
\text { (Molecular ions) }\end{array}$ & Ion abund. ratio \\
\hline \hline 2-Phenylethanethiomorpholide (I) & -9.0 & 5.1 & 0.1 \\
\hline 2-(3-Bromophenyl)ethanethiomorpholide (II) & -4.1 & 20.5 & 0.19 \\
\hline 2-(2,4-Dimethylphenyl)ethanethiomorpholide (III) & -12.4 & 0 & 1.02 \\
\hline 2-( $\beta$-Naphtyl)ethanethiomorpholide (IV) & -9.8 & 0 & 0.62 \\
\hline N,N-Dimethylethanethioamide & -13.8 & 1.89 \\
\hline
\end{tabular}

*The heats of formation units are $\mathrm{kJ} \mathrm{mol}^{-1}$ and the mass spectral data are extracted from Table $\mathbf{1}$. 
Table 3. ${ }^{1}$ H NMR Data of Selected N,N-Disubstituted Thioamides (ppm, +/- 0.05)<smiles>S=C(CBr)N1CCOCC1</smiles><smiles>SC(Br)=C(S)CBr</smiles>

I Ar: phenyl

II Ar: 3-bromophenyl

III Ar: 2,4-dimethylphenyl

IV Ar: $\beta$-naphtyl

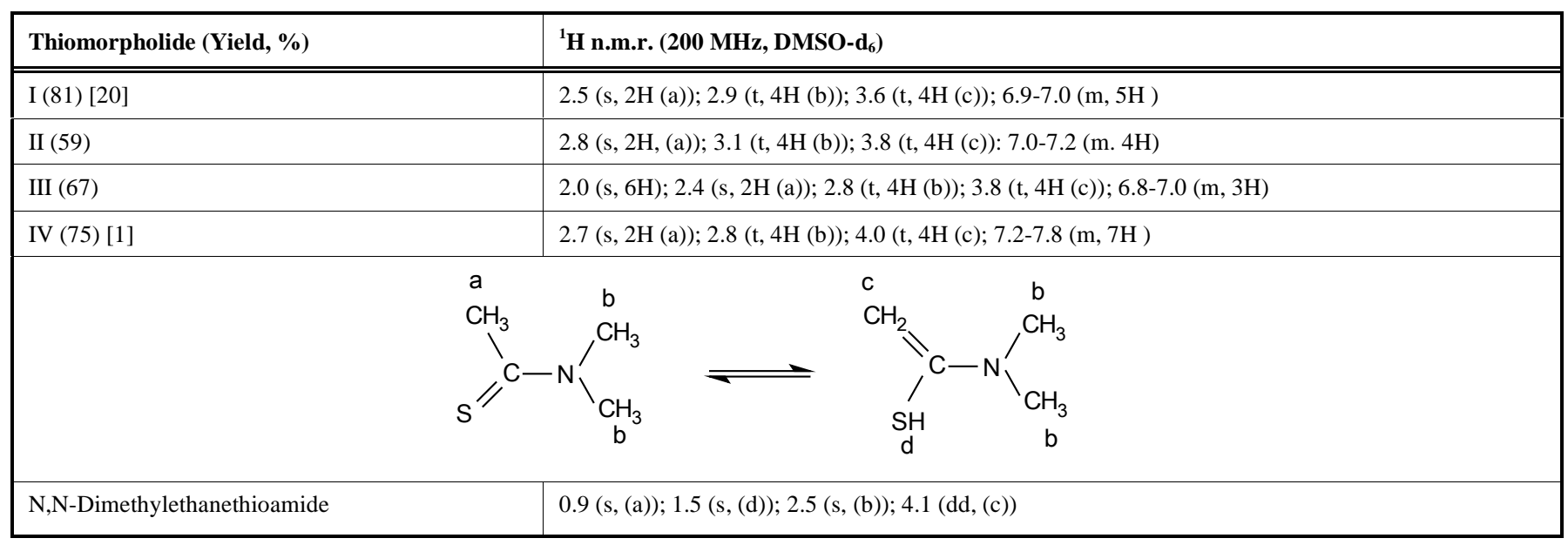

$\left(\mathrm{CSNC}_{4} \mathrm{H}_{8} \mathrm{O}\right)^{+}$for the estimation of the tautomerization position assuming that the response factor for each tautomer is quite similar.

The ion abundances in Table $\mathbf{1}$ were calculated as follows: (1000 x ion abundance / total ion abundance).

Table 2 shows the enol-keto heats of formation differences for the selected molecules and corresponding molecular ions (by AM1 calculations) and their correlation with experimental data.

Table 3 depicts ${ }^{1} \mathrm{H}$ n.m.r spectral data for the compounds under study to be evaluated in regard to tautomerism occurrence as an additional experimental support.

\section{DISCUSSION}

Schemes 1 and $\mathbf{2}$ show the fragmentation pathways of the thiomorpholides and of N,N-dimethylethanethioamide not only to understand their spectrometric behavior but also for the assignment of specific fragment ions to both tautomers.

As it can be observed in Table $\mathbf{1}$, the equilibrium position depends on the substituent nature taking into account electronic and steric effects. In related studies $[7,8]$ it was concluded that bulky substituents in the $\alpha$-carbon to the carbonyl group, shift the equilibrium towards the enol form, and this is observed when comparing in Table $\mathbf{1}$ the ion abundances ratio $(\mathrm{M}-\mathrm{SH})^{+} /\left(\mathrm{CSNC}_{4} \mathrm{H}_{8} \mathrm{O}\right)^{+}$for 2-phenylethane-<smiles>C[C+](C)C(C)(C)N(C)C#[S+]C(C)C</smiles>

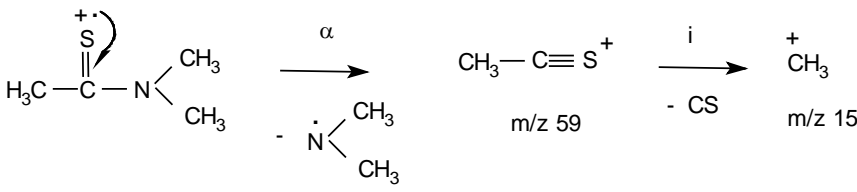<smiles></smiles>

Scheme 2. Main fragmentation pathways for N,N-Dimethylethanethioamide. 
thiomorpholide (I) and 2-( $\beta$-naphtyl)ethanethiomorpholide (IV) (0.34 vs. 0.62).

Besides, it is also observed that electron-donor substituents favor the occurrence of the thioimidol structure which is adequately illustrated by the ion abundances ratio for 2phenylethane thiomorpholide (I) and 2-(2,4-dimethylphenyl)ethanethiomorpholide (III) (0.34 vs. 1.02). Electronacceptor substituents exert the opposite effect: 2-phenylethanethiomorpholide (I) vs. 2-(3-bromo phenyl)ethanethiomorpholide (II) (0.34 vs. 0.19). Out of the comparison with the N,N-dimethyl ethanethioamide it could be inferred that the thiomorpholide group makes the enol tautomer less stable than the corresponding thioketo, probably due to steric and electronic effects (the bigger thiomorpholide group would interact sterically with the thiol group more strongly than with the thiocarbonyl group and besides, the morpholide oxygen electron-acceptor effect would be less detrimental on the zwitterionic canonical form describing the thioketo structure (with the positive charge on the nitrogen atom and the negative charge "comfortably" located on the sulfur atom) respect to the analogue thioenol.

It is well known that reactivities of neutral molecules and their corresponding molecular ions can be quite different so that it is very important to analyze the possibility of tautomerism occurrence between ionic species. In this sense, diverse families of compounds have been studied [10-17] and adequate support has been found by reporting that negligible influence on the tautomeric equilibrium position occurs after ionization in the ion source of the mass selective detector used to generate the experimental data.

Notwithstanding, to support that the observed tautomeric equilibria distributions come from the molecular species with negligible contribution from tautomerism of molecular ions, theoretical calculations of heats of formation were carried out for both species.

As in previous work [10-17], semiempirical AM1 results are used to determine the heats of formation differences which follow the same tendency observed by mass spectrometric results only in the case of the neutral molecules. For molecular ions no tendency is observed; for example the $\Delta \mathrm{H}$ for tautomerization of the 2-(2,4-dimethylphenyl)ethanethiomorpholide (III) should be lower than that for the 2phenylethane thiomorpholide (I) which is not the case (5.1 vs. $20.5 \mathrm{~kJ} \mathrm{~mol}^{-1}$ ).

Additional evidence in regard to tautomerism occurrence can be found by analysis of the ${ }^{1} \mathrm{H}$ n.m.r spectrum of N,Ndimethylethanethioamide (Table 3). As it can be observed the n.m.r. data obtained under the described experimental conditions allow to conclude that both tautomeric forms coexist in solution for this compound. For the thiomorpholides there is no direct evidence of the tautomers coexistence under the same experimental conditions.

\section{CONCLUSIONS}

Received: June 20, $2008 \quad$ Revised: August 11, $2008 \quad$ Accepted: Februray 21, 2009 (C) Allegretti et al.; Licensee Bentham Open.

This is an open access article licensed under the terms of the Creative Commons Attribution Non-Commercial License (http://creativecommons.org/licenses/by-nc/3.0/) which permits unrestricted, non-commercial use, distribution and reproduction in any medium, provided the work is properly cited.
As shown in several papers [10-17] the usefulness of mass spectrometry (and GC/MS) to predict tautomeric behavior is demonstrated here along with additional support provided by ${ }^{1} \mathrm{H}$ n.m.r. data and suitable theoretical calculations performed at the semi-empirical level via AM1 method. The mass spectra of N,N-disubstituted thioamides can provide valuable information regarding the keto-enol equilibria taking place in the gas phase (fast tautomerization equilibrium at the injection port of the gas chromatograph). The predictive value of this methodology is supported by the influence of the nature and size of substituents on tautomeric equilibria and the rather good correlation existing between the selected fragments abundances ratio and the heats of tautomerization determined theoretically via the semiempirical AM1 method. Results show that the thioketothioenol equilibrium can be studied by mass spectrometry and not only ionization in the ion source has a negligible effect on the position of that equilibrium but also the chromatographic conditions (with exception of the injection port) seem to exert no effect.

\section{REFERENCES}

[1] Murguia, M. C. ; Rossi, R. A. Terahedron Lett., 1997, 38, 1335.

[2] Metzner, P. Synthesis, 1992, 12, 1185.

[3] Spatola, A. F. In Chemistry and Biochemistry of Aminoacids, Peptides and Proteins; Weintstein, B., Ed., Marcel Dekker: New York, 1983, Vol. 7, pp. 267-357.

[4] Koike, K.; Jía, Z.; Nikaib, T.; Liu, Y.; Zhao, Y.; Guo, D. Org. Lett. 1999, $1,97$.

[5] Farina, C.; Pillegata, R.; Pinza, M.; Pifferi, V. Arch. Pharm., 1981, 314,108 .

[6] Ivan, L. P.; Richard, L. J.; Halina, T. S. Tetrahedron Lett., 2000, $41,1957$.

[7] Jarvest, R. L.; Pinro, I. L.; Ashman, S. M.; Dabrowski, G. E.; Fernandez, A. V.; Jenning, L. J. ; Lavery, P.; Tew, D. G. Bioorg. Med. Chem. Lett., 1999, 9, 443.

[8] Petrientt, P.; Kalandarishivilli, A. Mass Spectrom. Rev., 1966, 15, 339.

[9] Masur, M.; Nooshabadi, H. F. M.; Aghapoor, K.; Reza Darabi, H.; Mojahedi, M. M. Tetrahedron Lett., 1999, 40, 7549.

[10] Allegretti, P. E.; Milazzo, C. B.; Castro, E. A.; Furlong, J.J.P. J. Mol. Struct. Theochem., 2002, 589-590, 161-170.

[11] Allegretti, P. E.; Gavernet, L.; Castro, E. A.; Furlong, J. J. P. J. Mol. Struct. Theochem., 2000, 532, 139.

[12] Allegretti, P. E.; Labadie, G. R.; Gonzalez Sierra, M.; Furlong, J. J. P. Afinidad, 2000, VII, 485, 41.

[13] Allegretti, P. E.; Gavernet, L.; Castro, E. A.; Furlong, J. J. P. Asian J. Spectrosc., 2001, 5, 63.

[14] Allegretti, P. E.; Castro, E. A.; Furlong, J. J. P. J. Mol. Struct. Theochem., 2000, 499, 121.

[15] Allegretti, P. E.; Cánepa, A. S.; Bravo, R. D.; Castro, E. A.; Furlong, J. J. P. Asian J. Spectrosc., 2000, 4, 133.

[16] Allegretti, P. E.; Peroncini, V.; Castro, E. A.; Furlong, J. J. P. Int. J. Chem. Sci., 2003, $1,1$.

[17] Allegretti, P. E.; Cortizo, M. S.; Guzman, C.; Castro, E. A.; Furlong, J. J. P. Arkivoc, 2003, Part X, 24.

[18] Dewar, M. J. S.; Zoebisch, E. G.; Healy, E. F.; Stewart, J. J. P. J. Am. Soc., 1985, 107, 3902.

[19] Hyperchem ® 6.03 for Windows Molecular Modeling System, Hypercube Inc., Gainesville, FL. 2000.

[20] Carlson, R.; Landstedt, T; Shebana, R. Acta Chim. Scan. Ser. B., 1986, 40,534 . 